Article

\title{
From Batch to Flow Stripping Analysis with Screen-Printed Electrodes: A Possible Way to Decentralize Trace Inorganic Analysis
}

\author{
Carlo Dossi ${ }^{1, *(D)}$, Damiano Monticelli ${ }^{2}$, Andrea Pozzi 2 (D) and Sandro Recchia 2 \\ 1 Dipartimento di Scienze Teoriche ed Applicate, Università degli Studi dell'Insubria, \\ Via Dunant, 3, 22100 Varese, Italy \\ 2 Dipartimento di Scienza ed Alta Tecnologia, Università degli Studi dell'Insubria, \\ Via Valleggio, 11, 21100 Como, Italy; Damiano.Monticelli@uninsubria.it (D.M.); \\ Andrea.Pozzi@uninsubria.it (A.P.); Sandro.Recchia@uninsubria.it (S.R.) \\ * Correspondence: Carlo.Dossi@uninsubria.it; Tel.: +39-031-2386235
}

Received: 31 July 2018; Accepted: 3 September 2018; Published: 5 September 2018

\begin{abstract}
Decentralization of on-site and in-site trace metal analysis has been a key topic over the last 30 years, owing to the increasing need for environmental protection as well as industrial and health-based field applications. In trace (and ultratrace) metal analysis, electrochemical stripping analysis with mercury (or bismuth) screen-printed film electrodes has shown a fast growth in popularity thanks to the good limits of detection, the ease of application in the field, and the low cost. Moreover, the availability of new wall-jet flow cells has opened the opportunity for their use in in situ industrial monitoring. The analytical figures of merit in stripping voltammetry with screen-printed electrodes (SPEs) under decentralized conditions and/or with sensor arrays are heavily affected by some analytical factors, primarily the presence of a pseudo-reference electrode, the efficiency of mass transport during the preconcentration step, and the need for external calibration. A careful model investigation of the analytical parameters for an efficient use of SPEs in decentralized conditions has been undertaken and discussed. Different instrumental approaches were investigated, comparing optimized batch conditions and flow cell operation under either continuous flow or stopped-flow sample injection. The stripping efficiency under wall-jet flow conditions was found to be high and comparable to that in batch conditions, leading to sub-ppb ( $\mu \mathrm{g} / \mathrm{L})$ limit of detection (LOD) figures. Finally, external calibration in stripping voltammetry was studied as a viable alternative to conventional standard addition quantitation. Results showed, indeed, that external calibration was demonstrated to be reliable for quantitation of $\mathrm{Pb}$ and $\mathrm{Cd}$ in real water samples.
\end{abstract}

Keywords: stripping voltammetry; screen-printed electrodes; trace inorganic analysis; electroanalysis; batch vs flow cells

\section{Introduction}

Anodic stripping voltammetry (ASV) has always been regarded as an extremely sensitive electroanalytical technique and is often the greatest competition for plasma spectroscopies, particularly ICP-MS, for trace metal analysis [1]. These methods exploit the properties of certain electrodic materials to preconcentrate analytes-not just inorganic but also electroactive (bio)organic molecules—on their surface and analyze them by stripping back to the bulk of solution. Despite its toxicity, mercury still plays a major role in electrochemistry thanks to its physicochemical properties and its good analytical figures in electroanalysis, particularly robustness, reproducibility, and sensitivity for heavy metal determination [2-4]. The use of screen-printed electrodes (SPEs) was a second important step in stripping electroanalysis [5]. Apart from the low cost and excellent analytical performance in organic 
and bioanalytical chemistry [6,7], the microminiaturization of SPEs dramatically reduced the required amounts of metallic mercury, to the point of having it predeposited as salt on the working electrode, significantly reducing its environmental impacts [8]. In accordance with the European directive related to the restriction of metallic mercury, its substitution in favor of alternative metal coatings, such as bismuth or antimony, is an important research topic $[9,10]$. However, the need to investigate trace analytes under in-the-field and/or decentralized applications with potentially complex sample matrixes prompted us to continue using mercury(II) as the best choice for such study, thanks to the profound knowledge of its chemistry and electrochemical behavior [2-4]. Doubtless, bismuth(III) will be soon a viable alternative in this field, provided that a better understanding of its complex aqueous chemistry is reached [9].

The preconcentration step is the most critical aspect for in situ or in-the-field use of screen-printed electrodes in stripping analysis at trace levels. In fact, very low limits of detection and analytical sensitivities can only be reached by providing an optimized and reproducible mass transport to the electrode during the preconcentration step in batch conditions, as well as using a solvent exchange approach when complex matrixes are involved [11]. A different instrumental approach appeared in the " 80 s, involving the use of flow injection analysis for the stripping determination of trace analytes. It gained interest in the scientific community, with good analytical figures of merit and claimed patents [5,12], but it was apparently undergoing a slow oblivion. In recent years, however, this instrumental approach has resurfaced $[13,14]$. The availability of new, commercial low-volume wall-jet flow cells for screen-printed electrodes may be one of the main reasons for the revitalization of this technique. In organic chemistry, interesting results have already been reported [15]; more work seems, instead, to be needed for trace inorganic analysis. A recent preliminary report has shown how continuous flow operation seemed to be unsuited for their high noise, whereas flow injection was proposed as a reliable approach, with good limits of detection and reproducibility [16].

In this manuscript, a careful investigation of the analytical parameters for efficient use of SPEs in potential decentralized conditions is undertaken and discussed. Different instrumental approaches are investigated, comparing optimized batch conditions and flow cell operation, either under continuous flow or stopped-flow sample injection. Finally, external calibration in stripping voltammetry is studied, as a viable alternative to conventional standard addition quantitation.

\section{Materials and Methods}

\subsection{Instrumental Setup}

Screen-printed electrodes (SPEs) were bought from DropSens (DropSens S.L, Asturias, Spain). Electrodes were printed on a $33 \mathrm{~mm} \times 10 \mathrm{~mm} \times 0.5 \mathrm{~mm}$ ceramic alumina substrate under the code DRP-C110, with carbon electrodes for working and counter, and silver for the reference electrode. The surface area of the working carbon electrode is $16 \mathrm{~mm}^{2}$. In the presence of chloride in the sample solution, a film of $\mathrm{AgCl}$ is grown; the presence of chloride ions is therefore a necessary requirement for using SPEs in stripping analysis.

For electroanalytical experiments, an Amel 4330 versatile electroanalytical instrument (Amel Srl, Milano, Italy) was used. The Amel 4330 instrument proved very effective for stripping analysis because of its integrated voltammetric cell, which enables automatic stirring and degassing throughout all electroanalytic steps. Moreover, a Perimax 12 peristaltic pump (Spetec, Erding, Germany) for stopped-flow and flow injection operations can be easily interfaced.

The Amel4330 instrument, the batch cell, and the peristaltic pump are fully handled and controlled by the Windows-based VApeak software. This software has been developed by us to allow full instrumental control, as well as full data analysis (peak finding, peak height and area calculations), and quantitation via external calibration or standard additions without requiring any external modules.

All quantitative calculations were done as peak height. The conventional use of linear baselines can, however, result in underestimating peak heights in voltammetry [17]. The use of spline baselines 
in VApeak was suitably exploited to improve the reliability of the calibration calculations. Analytical sensitivity was defined as the slope of the best-fit calibration line. Limits of detection (LOD) were determined following IUPAC guidelines [18] as $3 \sigma / \mathrm{m}$, where $\sigma$ was determined by running ten replicate analyses on a standard sample near the limit of detection, and $\mathrm{m}$ is the analytical sensitivity. Limits of quantitation (LOQ) were then calculated as $10 \mathrm{\sigma} / \mathrm{m}$.

All the PTFE beakers and cells, round-bottomed flasks in polypropylene, polypropylene tubes, and pipette tips used for preparation and storage of samples and solutions were rinsed with copious amounts of double-distilled water.

Hydrochloric and nitric acid (TraceSelect from Fluka) were purified by sub-boiling distillation in a quartz-Teflon apparatus. Sodium chloride (Trace Select) was purchased from Fluka.

Cadmium and lead standard stock solutions (1000 mg/L) were from Sigma-Aldrich and diluted as required. Mercury stock solution $(80 \mathrm{mg} / \mathrm{L})$ was prepared from mercury(II) chloride (CarloErba, Milan Italy) in 1.3 M hydrochloric acid.

High-purity MilliQ water (from MilliPore, Burlington, MA, USA) was used for all solutions and standards, except if otherwise indicated.

\subsection{Cells and Flow System}

For performing stripping voltammetry under batch conditions, a specially designed, plastic-made cell (mod.4330-PX) was supplied by AMEL (\#1 in Figure 1A) and assembled on an Amel4330 instrument (Figure 1B).
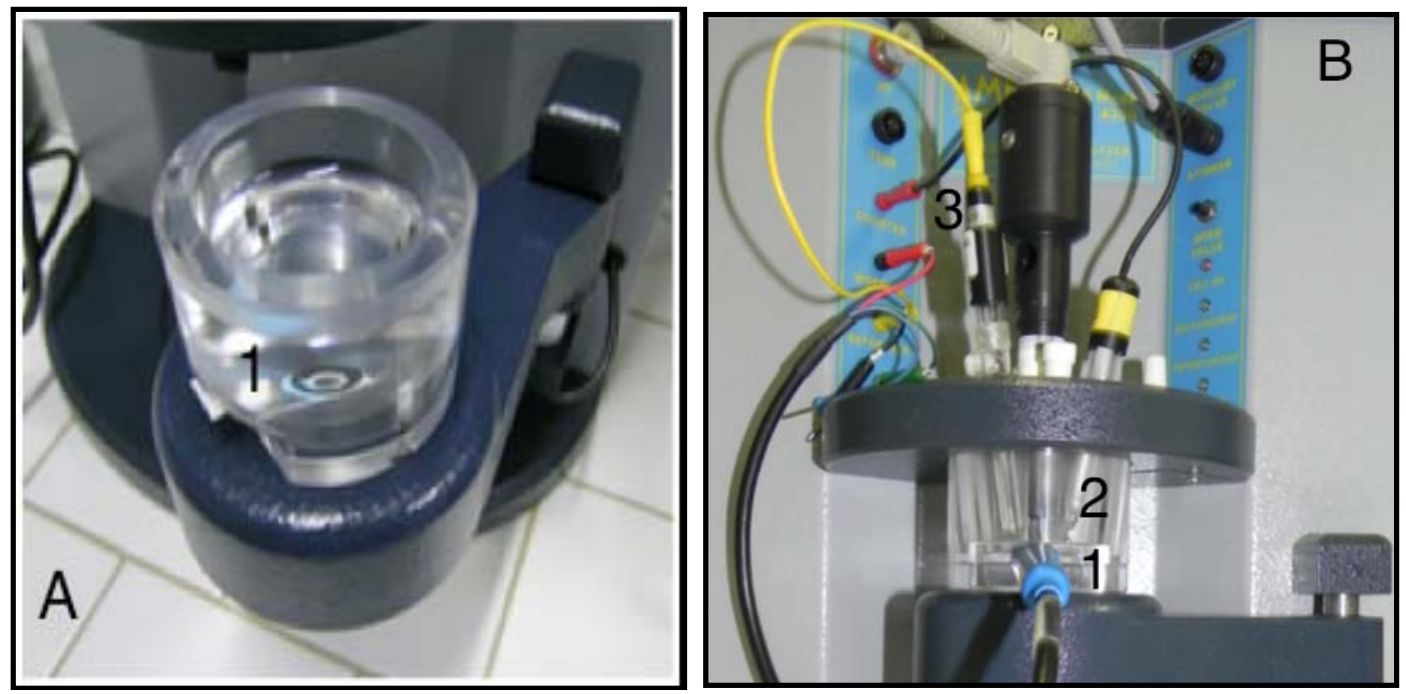

Figure 1. (A) The batch cell with screen-printed electrode (SPE) (A-1); (B) The assembled cell on an Amel4330 instrument: SPE cable connector (B-1); palette top stirrer (B-2); external electrodes (B-3).

The screen-printed electrode was placed on the bottom of the cell, kept in place, and sealed by a Viton O-ring. A palette top stirrer (\#2 in Figure 1B) was then placed above the active area of the electrode, and moved by a stepped motor in the range 0-800 rpm under computer control. In this way, mass transport to the electrode under stirred conditions was optimized, preventing, at the same time, water or acid vapors from degrading the electric contacts to the SPE. All experiments were conducted at $400 \mathrm{rpm}$. Moreover, this cell allowed the use of an external $3 \mathrm{M} \mathrm{KCl} \mathrm{Ag} / \mathrm{AgCl}$ reference electrode in order to reference all potentials (\#3 in Figure 1B). In those cases where the internal pseudo-reference Ag wire was used, a $0.01 \mathrm{M}$ chloride concentration had to be kept constant in the cell solution, and potentials were referred to the reference electrode.

The analytical step of analyte redissolution was initially done by differential pulse in the potential range between -1000 and $-250 \mathrm{mV}$ in order to account for all chloride activity. However, under 
our actual conditions, the stripping scan could be stopped at $-500 \mathrm{mV}$, to save analysis time. The differential pulse profile was performed with pulse height of $50 \mathrm{mV}$ and a voltage step of $5 \mathrm{mV}$. A final cleaning step was done at $-250 \mathrm{mV}$ for $10 \mathrm{~s}$.

The flow system was home-made in our laboratory using a Perimax 12 peristaltic cell, a six-port injection valve (Omnifit, Cambridge, UK) for the loading ("LOAD") and the injection ("INJECT") of samples in flow injection analysis (FIA) experiments, and a low-volume wall-jet Plexiglas flow cell DRP-FLWCL from Dropsens, Spain. The fluidic cell was run at $1.0 \mathrm{~mL} / \mathrm{min}$ flow of eluent in order to have best conditions inside the wall-jet cell.

The full instrumental scheme for flow stripping, for both stopped-flow and flow injection analysis, is depicted in Figure 2.

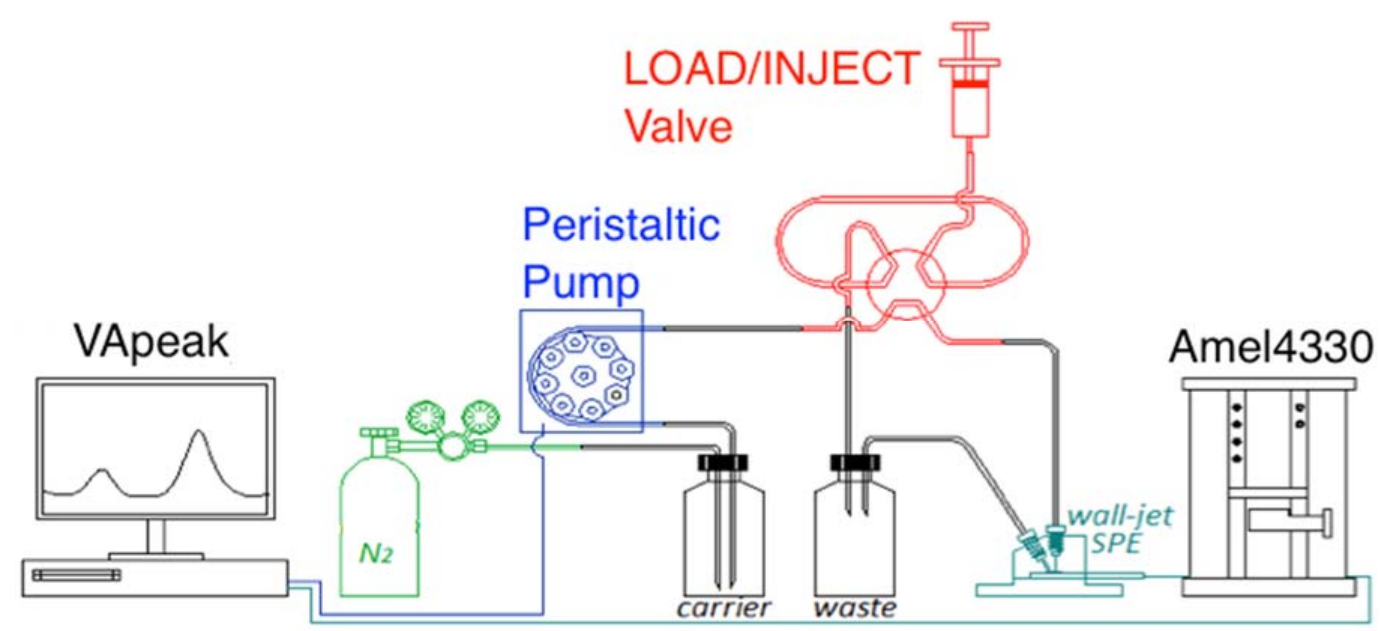

Figure 2. Instrumental scheme of the flow system to perform voltammetric stripping analyses under stopped-flow (SF-SV) or under flow injection analysis (FIA-SV).

For stopped-flow stripping voltammetry (SF-SV), the peristaltic pump was operated in the preconcentration and cleaning step, whereas it was switched off during the stripping analytical step. The complete flow timing is described in Figure 3.

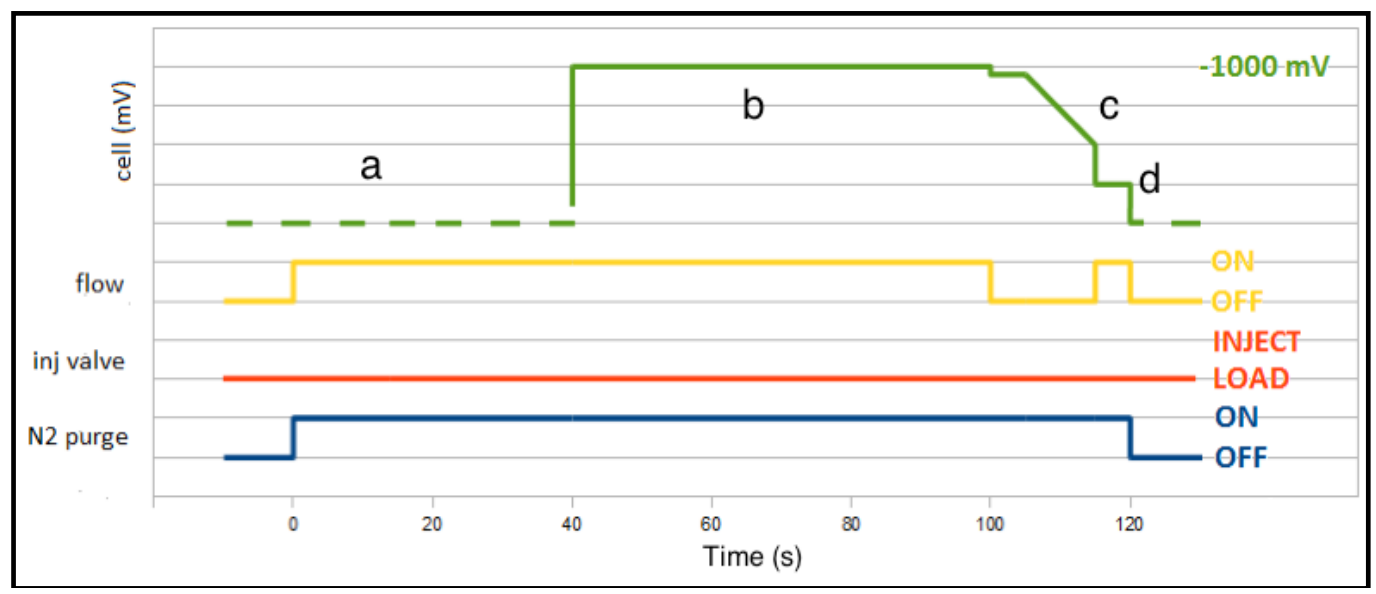

Figure 3. Timing diagram of stopped-flow operation in the stripping voltammetric analysis of $\mathrm{Pb}$ and Cd. Steps: (a) optional preanalysis degassing under open-cell condition; (b) preconcentration; (c) stripping analysis; (d) cleaning. Lines: Green, solid line: applied cell potential; Green, dashed line: open-cell conditions, with no current flowing. Yellow: sample flow; Red: injection valve position; Blue: $\mathrm{N}_{2}$ purge. 
For flow injection analysis stripping voltammetry (FIA-SV), the standard and sample solutions were injected via the Omnifit valve equipped with a $0.5 \mathrm{~mL}$ loop. The flow timing procedure was kept similar to that reported in Reference [16]. The setup of the fluidic system was performed using potassium ferricyanide ( $50 \mathrm{mM}$ in $1 \mathrm{M} \mathrm{KNO}_{3} / 0.1 \mathrm{M} \mathrm{KCl}$ solution) reduction as a model reaction at $0 \mathrm{mV}$ and amperometric detection.

For both flow injection and stopped-flow experiments, the fluidic setup was kept unchanged in order to allow a full comparison of the analytic performance in the two types of operation. Obviously, the Omnifit injection valve was operated only for flow injection analyses.

\subsection{Measurement Procedures}

Prior to the analysis, screen-printed electrodes were cleaned in ethanol, rinsed in water, and left in a $0.01 \mathrm{M}$ hydrochloric acid solution. No problems of lead contamination were found. Screen-printed electrodes were used in a standard 3-wire configuration.

For comparison purposes, an external $\mathrm{Ag} / \mathrm{AgCl}(3 \mathrm{M} \mathrm{KCl})$ electrode was used as a reference in the batch cell instead of the internal Ag electrode of the SPE. The chloride ion activity had to be kept constant throughout all experiments.

Prior to any analysis, a mercury film was grown on the working electrode using a plating solution of $80 \mathrm{mg} / \mathrm{L} \mathrm{HgCl}_{2}$ in $1.3 \mathrm{M} \mathrm{HCl}$ at $-1000 \mathrm{mV}$ under a stirring (or flowing) time of $200 \mathrm{~s}$. The analysis can theoretically be performed on this film without any other addition of the mercury salt. However, it was found that the addition of a 100-fold diluted plating solution to standards and samples greatly increased the reproducibility of the analysis. This is well known in the literature, since the diluted mercury solution helped to stabilize the mercury film and made the amalgam formation easier.

In flow analysis, a $0.8 \mathrm{mg} / \mathrm{L} \mathrm{HgCl}_{2}$ solution at $\mathrm{pH}=2$ and $\mathrm{a}_{\mathrm{Cl}}{ }^{-}=10^{-2} \mathrm{M}$ was used as the blank and eluent solution.

Between each sample, rinsing of the cell and the SPE surface was done with MilliQ water acidified to $\mathrm{pH}=2$ with hydrochloric acid. In all solutions, if the chloride activity was different from $10^{-2} \mathrm{M}$, sodium chloride or nitric acid were used for adjustment, and stripping potentials were corrected for chloride activity.

For standard addition quantitation, the sample was analyzed first. Then, three additions of a multistandard containing both $\mathrm{Cd}$ and $\mathrm{Pb}$ to reach a final standard concentration of around 15 and $25 \mu \mathrm{g} / \mathrm{L}$ were performed and the effects analyzed.

External calibration was done before the samples were analyzed by using a linear calibration line. A series of five standard solutions containing $\mathrm{Pb}$ and $\mathrm{Cd}$ in a range between 0 and the limit of linearity (LOL) were prepared in the same matrix as the samples (in our case, an acidified synthetic water). Normally, calibration is performed between 0 and $25 \mu \mathrm{g} / \mathrm{L}$.

The five standard solutions were sequentially analyzed, and the best fit was computed to obtain the calibration line. The samples were then analyzed and the two analytes were quantified using the parameters of the best-fit calibration line.

\section{Results and Discussion}

\subsection{From Batch to Stopped-Flow Differential Pulse Stripping Voltammetry}

One the most critical aspects of screen-printed electrodes is the intrinsic pseudo-reference character of the silver electrode, since potentials are dependent on the halide activity in the analyte solution. The $\mathrm{Cd}$ and $\mathrm{Pb}$ signals in batch stripping analysis on a water solution of around $\mathrm{pH}=2$ with $\mathrm{HCl}$ were compared using either the internal silver electrode of the screen-printed electrode or an external $3 \mathrm{M} \mathrm{KCl} \mathrm{Ag} / \mathrm{AgCl}$ electrode. This was made possible thanks to the versatility of the AMEL batch cell, which allows both reference electrodes to be used and easily selected. A signal shift of about $150 \mathrm{mV}$ towards more negative potential is observed using the internal Ag electrode of the SPE, in agreement with a quasi-Nernstian behavior. A more detailed investigation of the SPE at different chloride ion 
activities is shown in Figure 4. The red trace is the blank solution, with following additions of $5 \mu \mathrm{g} / \mathrm{L}$ each of $\mathrm{Cd}$ and $\mathrm{Pb}$ standard solution.

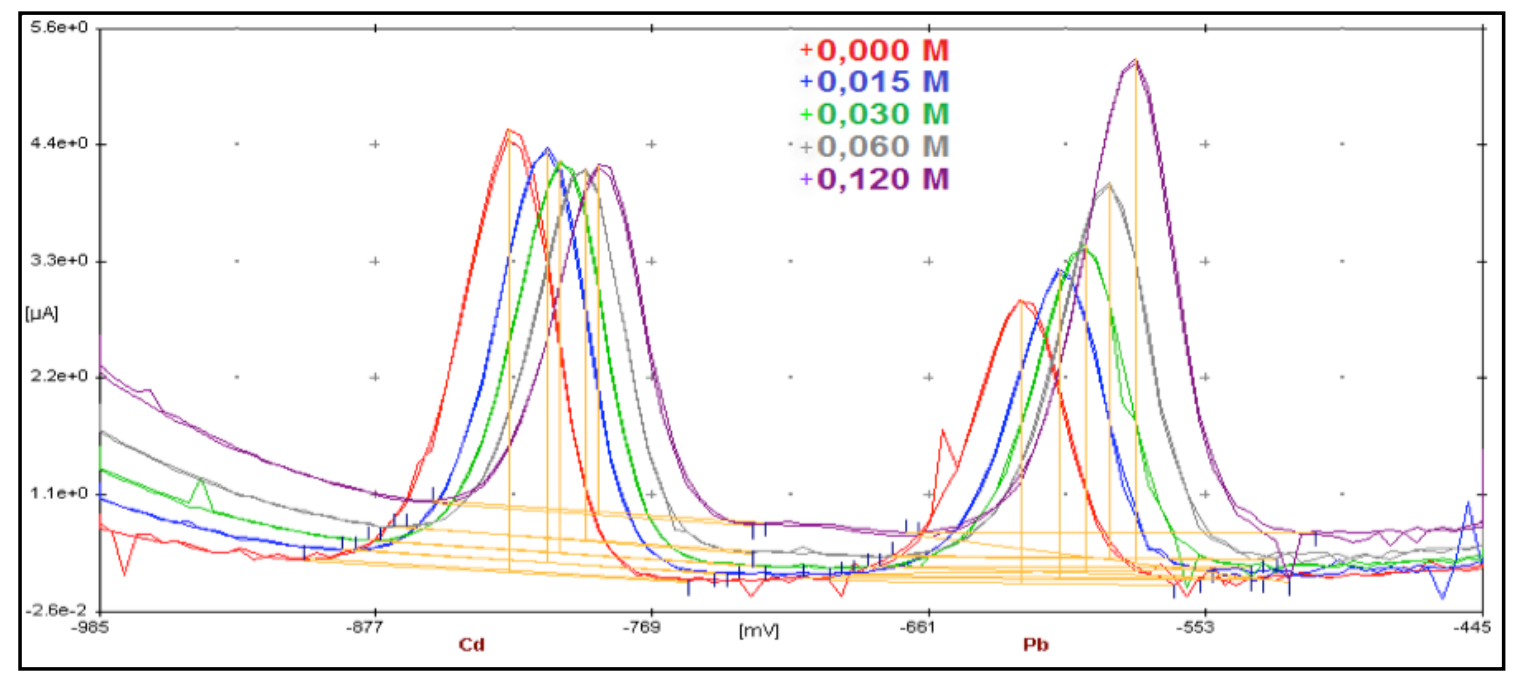

Figure 4. Stripping analysis of $\mathrm{Pb}$ and $\mathrm{Cd}$ at $15 \mu \mathrm{g} / \mathrm{L}$ at $\mathrm{pH}=2$ and chloride ion activity of $10^{-2}$ M. Effect of the addition of chloride ions on stripping signals using the internal pseudo-reference Ag electrode.

Interestingly, the potential shift with changing chloride ion activity is accompanied by a change in the analytical sensitivity of $\mathrm{Cd}$ and $\mathrm{Pb}$ in particular. This observation is not unexpected, because of the different speciation chemistry of the two metals. However, two important consequences can be seen. On one side, deposition potentials always have to be corrected for the actual chloride activity; on the other side, the chloride concentration has to be taken as constant during all calibration and quantitation steps.

The analytical behavior of the stripping analysis of cadmium and lead between 0 and $15 \mu \mathrm{g} / \mathrm{L}$ was compared between batch (Figure 5A) and stopped-flow conditions (Figure 5B).

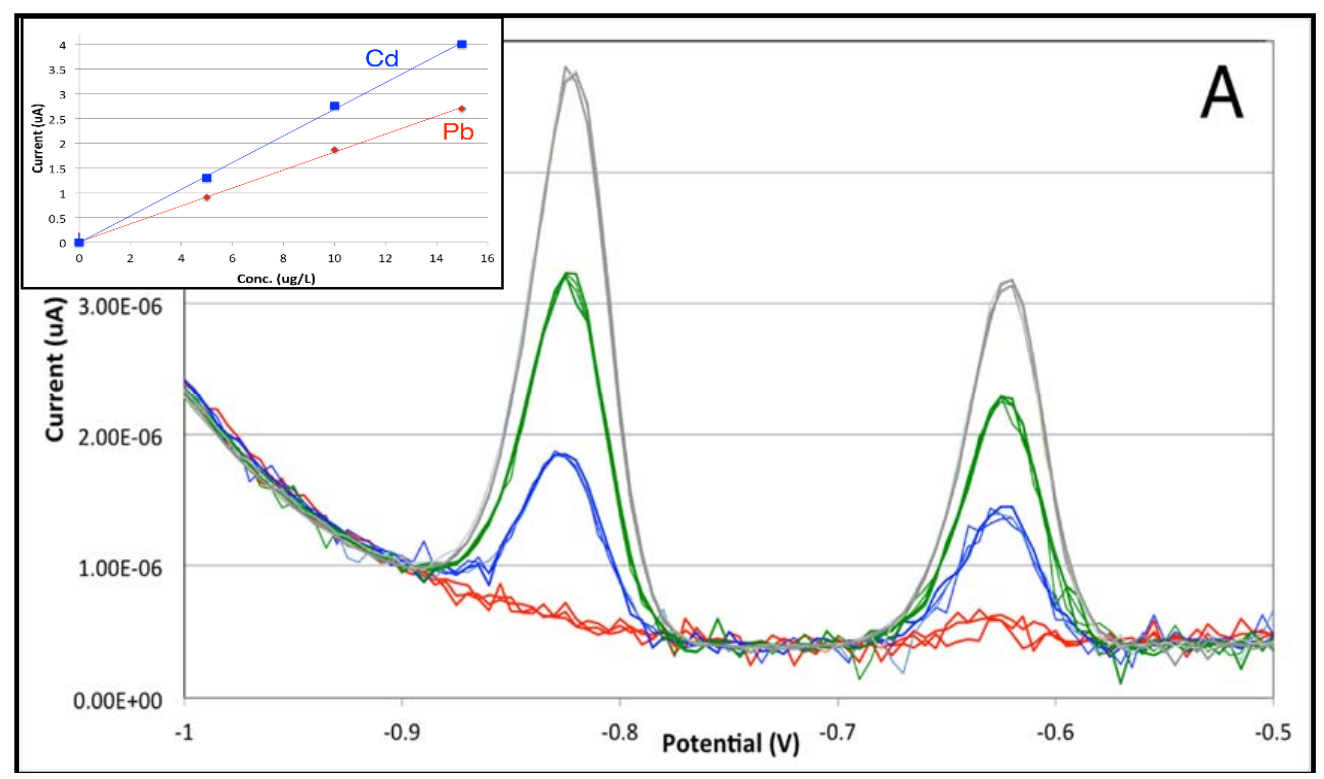

Figure 5. Cont. 


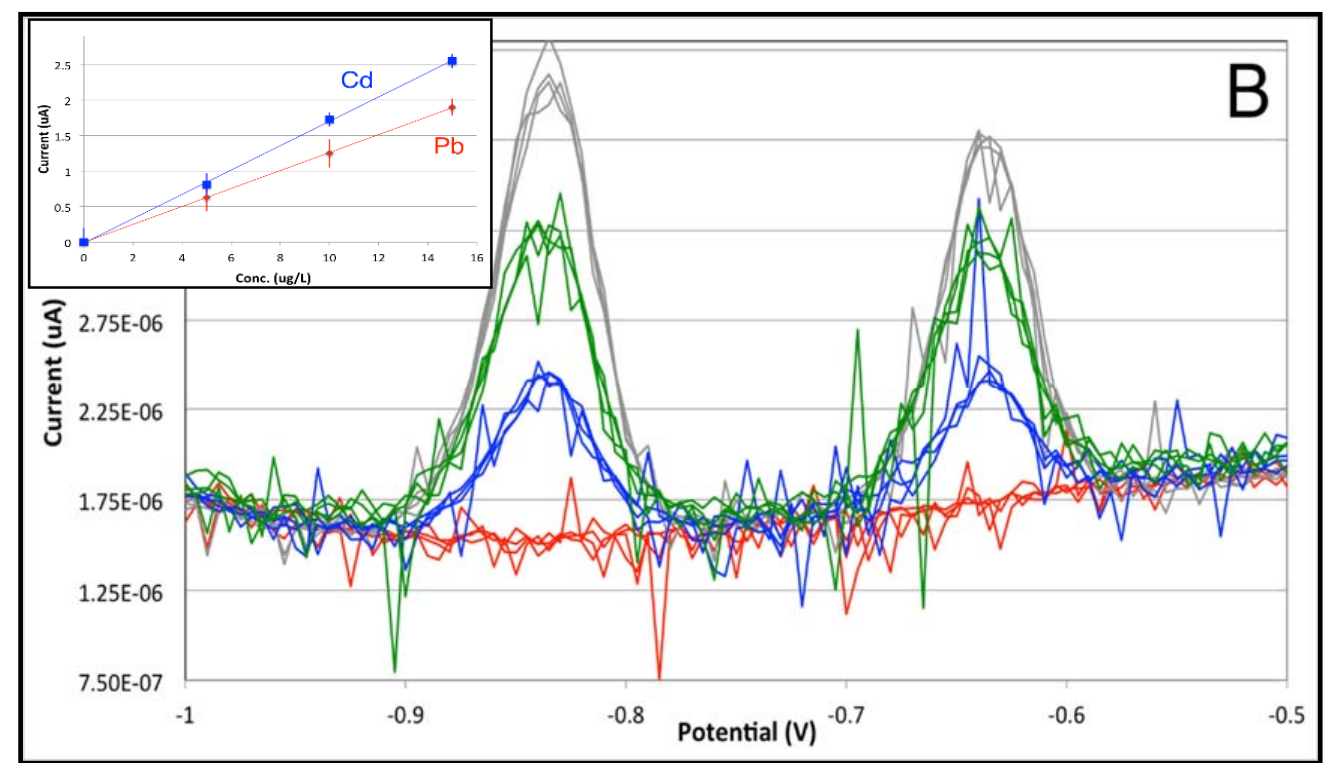

Figure 5. Comparison of stripping analysis signals of $\mathrm{Pb}$ and $\mathrm{Cd}$ between 0 and $15 \mu \mathrm{g} / \mathrm{L}$ with a preconcentration time of $60 \mathrm{~s}$. (A) Using batch cell; (B) using stopped-flow conditions. Inset: Calibration lines for $\mathrm{Cd}$ (in blue) and $\mathrm{Pb}$ (in red). Reference electrode: internal pseudo-reference.

It is immediately evidenced that the intensity of the stripping signals is similar within a factor of 2 in the batch and flow cells, indicating that the efficiency of mass transfer to the working electrode is similar in both cases. However, the use of the flow cell leads to a higher noise contribution, although its typical spike appearance may be removed by moving median filtering followed by low-order Savitsky-Golay smoothing [19]. Both features are already integrated into the VApeak software and can be performed automatically, if necessary. Accordingly, the analytical figures of merit calculated for the two calibration curves (Table 1) show that the sensitivity and intercepts are quite similar, whereas limits of detection and of quantitation are lower for the batch cell. Interestingly, the LODs for $\mathrm{Pb}$ and $\mathrm{Cd}$ in the batch cell are well under $0.1 \mu \mathrm{g} / \mathrm{L}$, approaching those classically reported for mercury-film-coated glassy carbon electrodes; the advantages of SPEs in terms of cost and versatility are now fully demonstrated.

Table 1. Figures of merit of $\mathrm{Cd}$ and $\mathrm{Pb}$ analysis under differential pulse stripping voltammetry. Comparison between batch and stopped-flow conditions.

\begin{tabular}{clcc}
\hline Cell Type & \multicolumn{1}{c}{ Figure of Merit } & Cd & Pb \\
\hline \multirow{3}{*}{ Batch } & Sensitivity $\left(\mu \mathrm{A} \times \mathrm{L} \times \mu \mathrm{g}^{-1}\right)$ & 0.2831 & 0.1681 \\
& Intercept $(\mu \mathrm{A})$ & -0.306 & 0.098 \\
& Limit of Detection $(\mu \mathrm{g} / \mathrm{L})$ & 0.17 & 0.19 \\
& Limit of Quantitation $(\mu \mathrm{g} / \mathrm{L})$ & 0.58 & 0.64 \\
\hline \multirow{3}{*}{ Stopped-Flow } & Sensitivity $\left(\mu \mathrm{A} \times \mathrm{L} \times \mu \mathrm{g}^{-1}\right)$ & 0.1635 & 0.1202 \\
& Intercept $(\mu \mathrm{A})$ & 0.189 & 0.279 \\
& Limit of Detection $(\mu \mathrm{g} / \mathrm{L})$ & 0.58 & 0.62 \\
& Limit of Quantitation $(\mu \mathrm{g} / \mathrm{L})$ & 1.98 & 2.06 \\
\hline
\end{tabular}

This difference in the analytical sensitivities between batch and stopped-flow conditions can likely be ascribed to restricted diffusion inside the low-volume flow cell, since the speciation chemistry is kept unchanged. However, it is harmless for analytical purposes, provided that the fluidodynamic conditions are kept constant and reproducible. 
An important point to be investigated relating to screen-printed electrodes under stirred or flow conditions is the repeatability between different electrodes and the durability of the active electrode surfaces. A comparison among three different screen-printed electrodes shows how the standard deviations for the analytical sensitivity are always below $10 \%$ for both analytes.

The durability of the electrode was then investigated by repeating standard calibration analysis. The analytical sensitivity slowly decreases with the increasing number of analysis rounds, reaching a $10 \%$ decrease from the initial value after 150 analyses for $\mathrm{Cd}$ and over 200 analyses for Pb. After 200 analyses, the electrode surface is significantly modified, which is particularly evident for the working and counter electrodes (Figure 6).

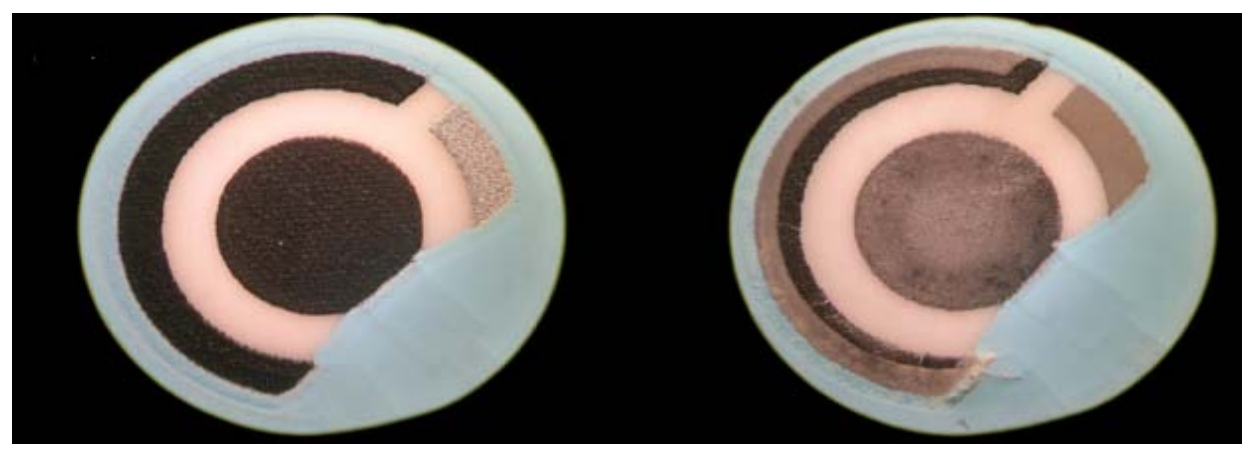

Figure 6. Optical microscopy pictures of the surface of the screen-printed electrode before (left) and after (right) performing 200 stripping voltammetric analyses. Experimental conditions as in Figure 4.

The degradation of the counter electrode was not found to be relevant, since the use of an external glassy carbon electrode as counter did not improve analytical figures of merit. Consequently, the degradation of the analytical sensitivity with increasing analysis number is to be attributed to surface modifications of the working electrode only.

The main difference between batch and flow techniques is the methodology used for the quantitative analysis. Under batch conditions, quantitation is well known to be easily done via standard additions, and no further investigation has been done. Accordingly, acidified tap water samples from the town of Como were analyzed after being spiked at $5 \mu \mathrm{g} / \mathrm{L}$; recoveries in the $95-105 \%$ range were found for both lead and cadmium.

Under flow conditions, instead, standard addition is quite clumsy to perform and almost impossible if a continuous flow of sample is analyzed for automated decentralized analysis. External calibration was then found to be particularly suited for stopped-flow stripping, either for the simplicity of changing standards and samples or for the reproducibility that is guaranteed by the instrumental setup. The VApeak software was particularly efficient in this respect since it has a dedicated section for external calibration in stripping analysis.

The calibration under stopped flow was performed with five standards of $\mathrm{Pb}$ and $\mathrm{Cd}$ between 0 and $25 \mu \mathrm{g} / \mathrm{L}$. A series of synthetic water samples was then analyzed; results are shown in Table 2.

The samples were analyzed in random order to avoid error accumulation. It is noteworthy that all samples analyzed are within a maximum error of $10 \%$, with deviations from certified values mostly in the $\pm 3 \%$ level. The analytical reproducibility was always found to remain in this range.

This result is quite important in light of decentralizing SPE-based techniques in the field, such as for continuous monitoring of real streams, where addition of standards is really unpractical. 
Table 2. Reference sample analyses in stopped-flow stripping voltammetry with external calibration. Flow $=1.0 \mathrm{~mL} / \mathrm{min}$; Preconcentration time $=60 \mathrm{~s}$.

\begin{tabular}{ccccc}
\hline Analyte & Peak Height $(\boldsymbol{\mu A})$ & $\begin{array}{c}\text { Calculated Concentration } \\
(\boldsymbol{\mu g} / \mathbf{L})\end{array}$ & $\begin{array}{c}\text { Expected Concentration } \\
(\boldsymbol{\mu g} / \mathbf{L})\end{array}$ & \% Recovery \\
\hline \multirow{3}{*}{$\mathrm{Cd}$} & 2.4449 & 15.28 & 15 & $102 \%$ \\
& 0.8463 & 5.11 & 5 & $105 \%$ \\
& 4.3753 & 27.56 & 25 & $110 \%$ \\
& 3.3041 & 20.75 & 20 & $103 \%$ \\
$\mathrm{~Pb}$ & 1.5945 & 9.87 & 10 & $99 \%$ \\
\hline & 1.9857 & 14.49 & 15 & $96 \%$ \\
& 0.6657 & 4.57 & 5 & $91 \%$ \\
& 3.4794 & 25.72 & 25 & $103 \%$ \\
& 2.6807 & 19.72 & 20 & $98 \%$ \\
\end{tabular}

\subsection{From Stopped-Flow to Flow Injection Analysis in Differential Pulse Stripping Voltammetry}

The major disadvantage of stopped-flow operations in stripping voltammetry is the noise occurring during the redissolution step. The source of this noise is likely to be ascribed to two major causes, one being related to bubble formation on the electrode surface and the other to the low volume of the wall-jet cell. However, the use of flow injection during the deposition step has been proposed to improve both noise and analytical reproducibility in flow stripping analysis [16]. Our instrumental setup was then devised in order to make a direct comparison between stopped-flow and flow injection conditions for stripping voltammetry. The shape and the reproducibility of injection peaks werre investigated using ferricyanide reduction as model reaction under amperometric detection (Figure 7).

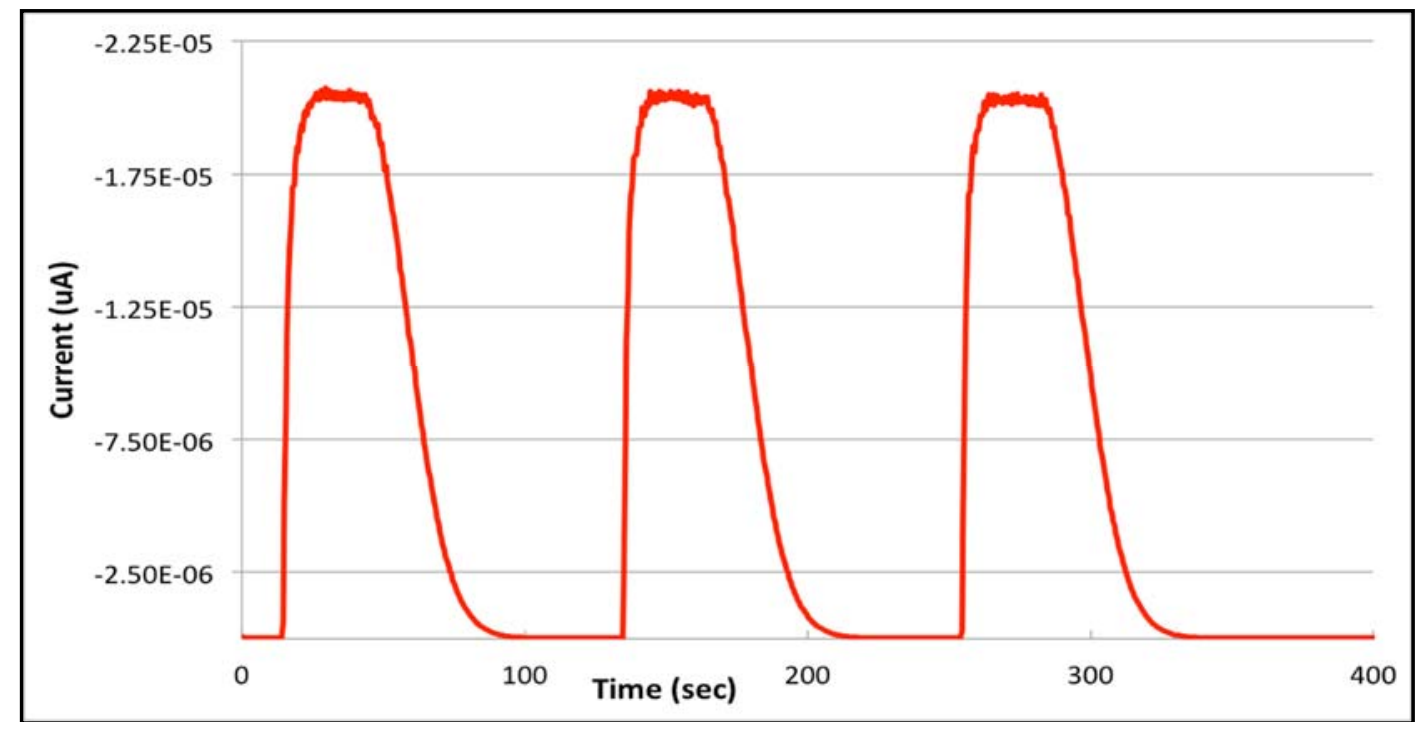

Figure 7. Shape and reproducibility of consecutive flow injection analyses in potassium ferricyanide reduction at $0 \mathrm{mV}$ as model reaction.

In accordance with a low-dispersion system, the FIA peaks showed rectangular shapes with fast recovery to baseline [20]. The injection peak is considered terminated within $100 \mathrm{~s}$ without any carryover. This is important for calculating the correct timing for stripping steps in FIA-SV. Moreover, reproducibility between consecutive injections was found to be excellent.

The analytical redissolution step was then performed under identical fluidic conditions, under quiescent solution in the cell: the sample for stopped flow, or pure electrolyte for flow injection. A preliminary investigation of flow-injection stripping voltammetry of $\mathrm{Pb}$ and $\mathrm{Cd}$ between 0 and 
$25 \mu \mathrm{g} / \mathrm{L}$ was very indicative of the correct implementation of the fluidic setup, giving good linearity and a relatively low background noise level. A comparison of the analytical performance between SF-SV and FIA-SV was done on a synthetic water sample at a Pb and Cd concentration of $15 \mu \mathrm{g} / \mathrm{L}$ (Figure 8).

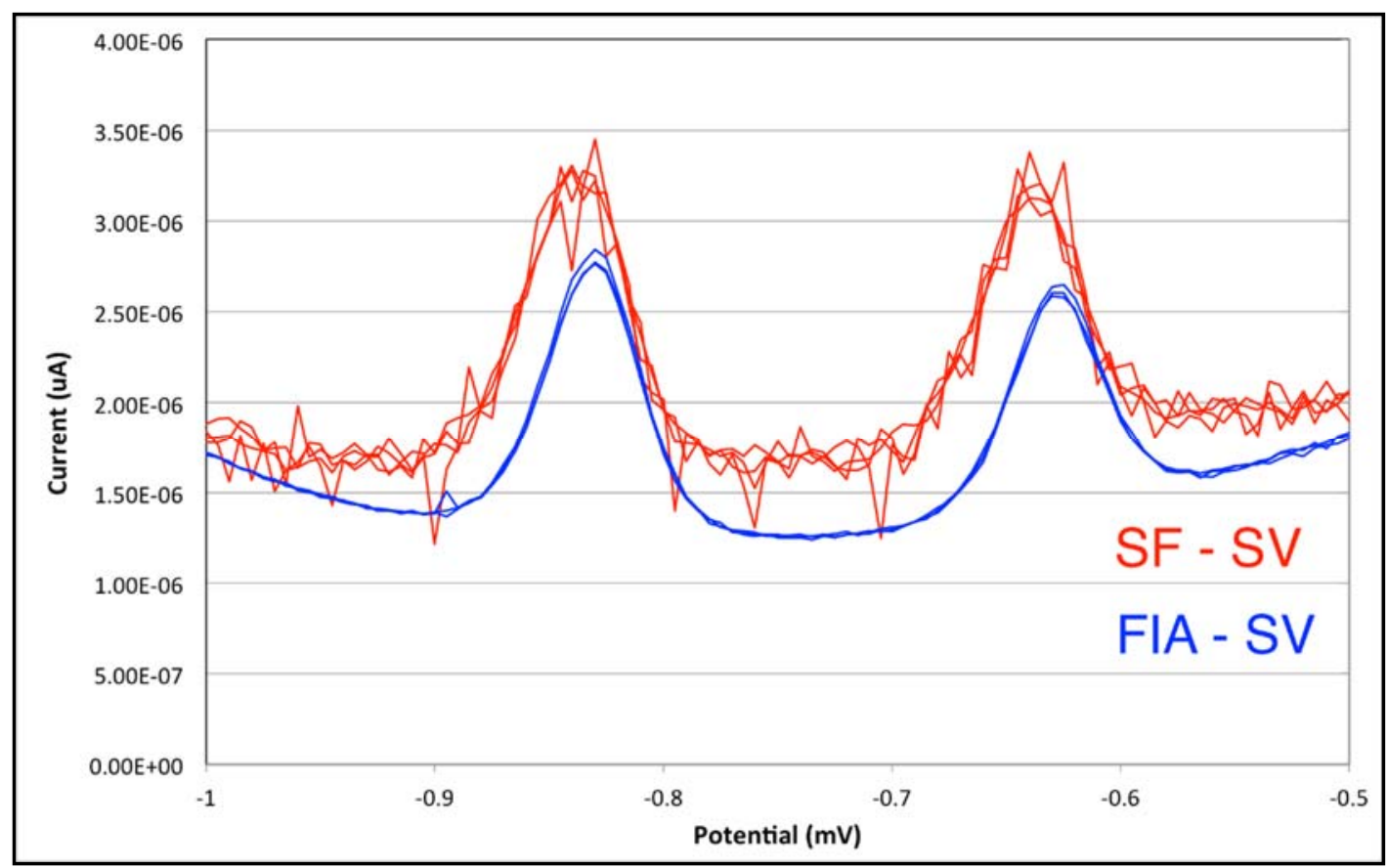

Figure 8. Comparison of analytical signals of $\mathrm{Pb}$ and $\mathrm{Cd}$ at $15 \mu \mathrm{g} / \mathrm{L}$ obtained in stopped-flow (SF-SV red trace) and in flow injection (FIA-SV blue trace) stripping voltammetry.

It is immediately evident that the flow injection analysis shows significantly lower noise than does stopped-flow analysis. A simplistic view of noise arising from microbubble formation at the electrode surface should therefore be discarded. It appears plausible that the noise is related to the presence of the sample inside the low-volume flow cell, maybe influencing the ideal diffusion control of $\mathrm{Pb}$ and $\mathrm{Cd}$ re-dissolving into the solution. In any case, the stopped-flow technique will always be very sensitive to the sample matrix. Consequently, flow injection stripping voltammetry will be the technique of choice particularly with complex matrix samples, since the analytical step is always done in pure eluent solution.

A detailed investigation of the analytical figures of merit was then undertaken, with particular emphasis on the analytical sensibility for inter-electrode reproducibility and limits of detection (Table 3).

Table 3. Reproducibility and figures of merit of $\mathrm{Cd}$ and $\mathrm{Pb}$ analysis under flow-injection analysis differential pulse stripping voltammetry.

\begin{tabular}{clcc}
\hline Measure Type & Figure of Merit & $\mathbf{C d}$ & $\mathbf{P b}$ \\
\hline \multirow{2}{*}{ Electrode 1 } & Sensitivity $\left(\mu \mathrm{A} \times \mathrm{L} \times \mu \mathrm{g}^{-1}\right)$ & 0.1382 & 0.09095 \\
& Intercept $(\mu \mathrm{A})$ & -0.1854 & -0.0936 \\
\hline \multirow{2}{*}{ Electrode 2 } & Sensitivity $\left(\mu \mathrm{A} \times \mathrm{L} \times \mu \mathrm{g}^{-1}\right)$ & 0.1363 & 0.08795 \\
& Intercept $(\mu \mathrm{A})$ & -0.3284 & -0.1461 \\
\hline \multirow{2}{*}{ Electrode 3 } & Sensitivity $\left(\mu \mathrm{A} \times \mathrm{L} \times \mu \mathrm{g}^{-1}\right)$ & 0.1335 & 0.09007 \\
& Intercept $(\mu \mathrm{A})$ & -0.450 & -0.1820 \\
\hline \multirow{2}{*}{ Mean result of three electrodes } & Limit of Detection $(\mu \mathrm{g} / \mathrm{L})$ & 0.32 & 0.35 \\
& Limit of Quantitation $(\mu \mathrm{g} / \mathrm{L})$ & 1.06 & 1.08 \\
\hline
\end{tabular}


The analytical sensitivities are lower than those found in stopped flow. In flow injection stripping, the preconcentration step is, in fact, related not to the deposition time, as in conventional batch or stopped-flow stripping, but to the loop volume, which is injected during the preconcentration step. The duration of the preconcentration step is, therefore, not related to the desired enrichment of the analytes at the mercury electrode, but has to be selected in order to have the injected peaks returning to baseline before starting the analytical step of analyte redissolution. The sensitivity in this approach is easily increased by changing the loop volume as desired, and setting the preconcentration time as a function of peak duration.

Apparently, there are few problems of saturation of the mercury film. The linearity in the calibration curves for both $\mathrm{Pb}$ and $\mathrm{Cd}$ is excellent, with $\mathrm{LOL}$ values up to $100 \mu \mathrm{g} / \mathrm{L}$; the curves then tend to bend at higher concentrations, as can be expected (Figure 9).

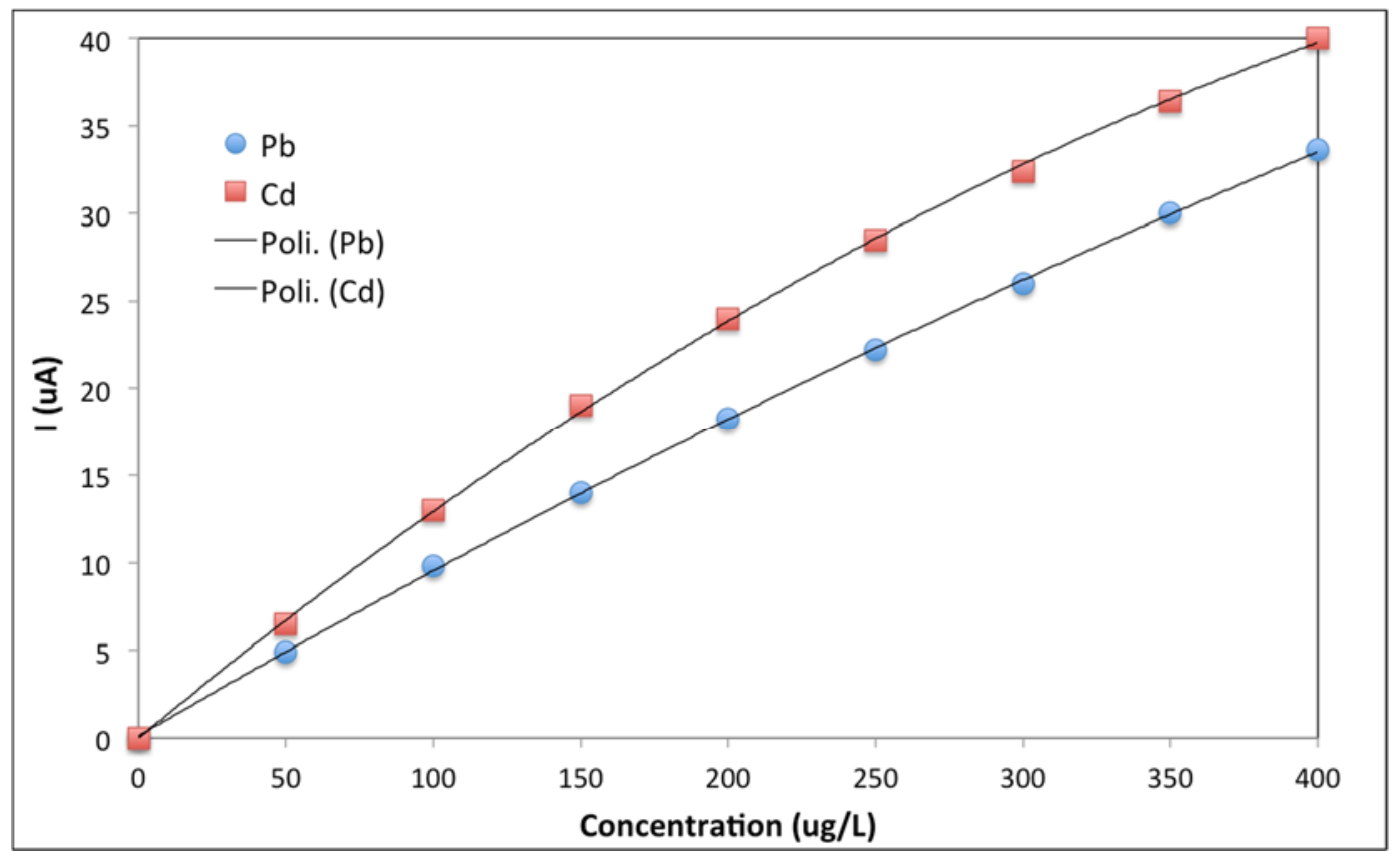

Figure 9. Calibration curves in flow injection analysis stripping voltammetry for $\mathrm{Pb}$ and $\mathrm{Cd}$ between 0 and $400 \mu \mathrm{g} / \mathrm{L}$. Discrete points: experimental data; black lines: second-order polynomial interpolating curves.

Quantitative analysis results were studied via external calibration within the limit of linearity of $100 \mu \mathrm{g} / \mathrm{L}$. Provided that samples and standards shared the same matrix, results were found to be similar to those reported for the stopped-flow stripping voltammetry. Analytical results for three acidified tap water samples spiked at $5 \mu \mathrm{g} / \mathrm{L}$ with lead and cadmium are summarized in Table 4 . Similar conclusions were reported in a recent investigation [16].

Table 4. Stripping analysis of $\mathrm{Cd}$ and $\mathrm{Pb}$ under flow-injection analysis differential pulse stripping voltammetry on spiked samples at $5 \mu \mathrm{g} / \mathrm{L}$ with lead and cadmium.

\begin{tabular}{ccccc}
\hline & \multicolumn{2}{c}{ Cd } & \multicolumn{2}{c}{ Pb } \\
\cline { 2 - 5 } & Found $(\mu \mathrm{g} / \mathrm{L})$ & \%Recovery & Found $(\mu \mathrm{g} / \mathrm{L})$ & \% Recovery \\
\hline Sample 1 & 4.80 & $96 \%$ & 4.99 & $100 \%$ \\
Sample 2 & 4.51 & $90 \%$ & 4.60 & $92 \%$ \\
Sample 3 & 4.88 & $97 \%$ & 4.81 & $96 \%$ \\
\hline
\end{tabular}


However, it can already be estimated visually from Figure 9 that calibration curves for both $\mathrm{Pb}$ and Cd can be easily fitted by second-order polynomials. Quantitation is, thus, possible up to concentration levels around a few hundreds of $\mu \mathrm{g} / \mathrm{L}$ by exploiting the nonlinear calibration curve. This result will widen the application of flow injection stripping voltammetry since sample pretreatment and/or dilution is often unpractical for in situ analysis under a decentralized approach.

The limits of detection were calculated following IUPAC guidelines; values around $0.35 \mu \mathrm{g} / \mathrm{L}$ for $\mathrm{Pb}$ for $\mathrm{Cd}$ were found, which are similar to those found for the stopped-flow technique. A simple increase of the injected loop volume will immediately result in a decrease of the detection limits without any adverse effect thanks to the extended linearity of the flow injection technique.

\section{Conclusions}

Screen-printed electrodes have been demonstrated to play an increasing role in ultratrace inorganic chemistry, as already observed for organic analysis [15]. These results have been linked to a careful control of matrix chemistry, chloride ion activity in particular, and to the recent development of batch and flow cells for optimized hydrodynamic conditions during the preconcentration steps. Main results for batch, stopped-flow, and flow injection analysis are summarized in Table 5.

Table 5. Analytical figures of merit for stripping analysis of $\mathrm{Cd}$ and $\mathrm{Pb}$ under different conditions.

\begin{tabular}{|c|c|c|c|c|c|c|}
\hline & \multicolumn{2}{|c|}{ Batch } & \multicolumn{2}{|c|}{ Stopped Flow } & \multicolumn{2}{|c|}{ Flow Injection Analysis } \\
\hline & $\mathrm{Cd}$ & $\mathrm{Pb}$ & $\mathrm{Cd}$ & $\mathrm{Pb}$ & $\mathrm{Cd}$ & $\mathrm{Pb}$ \\
\hline Sensitivity $\left(\mu \mathrm{A} \times \mathrm{L} \times \mu \mathrm{g}^{-1}\right)$ & 0.2831 & 0.1681 & 0.1635 & 0.1202 & 0.1381 & 0.0909 \\
\hline Limit of Detection $(\mu \mathrm{g} / \mathrm{L})$ & 0.17 & 0.19 & 0.58 & 0.62 & 0.32 & 0.35 \\
\hline Analytical Errors & $<5 \%$ & $<5 \%$ & $<10 \%$ & $<10 \%$ & $<10 \%$ & $<10 \%$ \\
\hline Analysis Time ${ }^{a}$ & \multicolumn{2}{|c|}{$175 \mathrm{~s}$} & \multicolumn{2}{|c|}{$175 \mathrm{~s}$} & \multicolumn{2}{|c|}{$220 \mathrm{~s}$} \\
\hline Sample Volume & \multicolumn{2}{|c|}{$10-25 \mathrm{~mL}$} & \multicolumn{2}{|c|}{$1-2 \mathrm{~mL}$} & \multicolumn{2}{|c|}{$0.5 \mathrm{~mL}$ (loop volume) } \\
\hline
\end{tabular}

${ }^{\mathrm{a}}$ preconcentration time: $60 \mathrm{~s}$ for batch and stopped flow; $110 \mathrm{~s}$ at $0.5 \mathrm{~mL}$ loop for flow injection analysis.

Batch analysis still shows the best analytical figures of merit, particularly in terms of sensitivity and limits of detection. Flow cells are, however, rapidly filling the gap; flow injection is confirmed to be superior to stopped flow, both in terms of signal-to-noise ratio and sample consumption. Moreover, sample throughput is significantly increased in flow cells since external calibration can be used as the preferred method of quantitation with respect to standard addition.

Finally, the feasibility of using nonlinear calibration procedures for flow injection stripping voltammetry will open new and unexplored possibilities in screen-printed electrode/flow injection stripping voltammetry for in situ decentralized analysis in industrial environments. Provisions for mercury substitution in real working conditions are under investigation, as well as hardware and software developments to fulfill all analytical needs for decentralization.

Author Contributions: Conceptualization, C.D., D.M., A.P. and S.R.; Writing-original draft, C.D.

Funding: Research was funded by Fondo di Ateneo per la Ricerca (FAR)—Università degli Studi dell'Insubria.

Acknowledgments: Fabio Stropeni is gratefully acknowledged for his chemical expertise and for performing the laboratory experiments. The authors also wish to thank Bruno Giacomel and Flavio Villa of AMEL srl (Milano, Italy) for the electrochemical instrumentation and joint project collaboration, and PierPaolo Protti for scientific discussions.

Conflicts of Interest: The authors declare no conflict of interest. 


\section{References}

1. Ochsenkühn-Petropoulou, M.; Ochsenkühn, K.M. Comparison of inductively coupled plasma-atomic emission spectrometry, anodic stripping voltammetry and instrumental neutron-activation analysis for the determination of heavy metals in airborne particulate matter. Fres. J. Anal. Chem. 2001, 369, 629-632. [CrossRef]

2. Wang, J. Analytical Electrochemistry, 3rd ed.; Wiley: Hoboken, NJ, USA, 2006.

3. Ozkan, S.A. Principles and Techniques of Electroanalytical Stripping Methods for Pharmaceutically Active Compounds in Dosage Forms and Biological Samples. Curr. Pharm. Anal. 2009, 5, 127-143. [CrossRef]

4. Economou, A.; Fielden, P.R. Applications, potentialities and limitations of adsorptive stripping analysis on mercury film electrodes. Trends Anal. Chem. 1997, 16, 286-292. [CrossRef]

5. Wang, J. Decentralized Electrochemical Monitoring of Trace Metals: From Disposable Strips to Remote Electrodes. Analyst 1994, 119, 763-766. [CrossRef]

6. Arduini, F.; Amine, A.; Moscone, D.; Ricci, F.; Palleschi, G. Fast, sensitive and cost-effective detection of nerve agents in the gas phase using a portable instrument and an electrochemical biosensor. Anal. Bioanal. Chem. 2007, 388, 1049-1057. [CrossRef] [PubMed]

7. Arduini, F.; Cassisi, A.; Amine, A.; Ricci, F.; Moscone, D.; Palleschi, G. Electrocatalytic oxidation of thiocholine at chemically modified cobalt hexacyanoferrate screen-printed electrodes. J. Electroanal. Chem. 2009, 626, 66-74. [CrossRef]

8. Palchetti, I.; Laschi, S.; Mascini, M. Miniaturised stripping-based carbon modified sensor for in field analysis of heavy metals. Anal. Chim. Acta 2005, 530, 61-67. [CrossRef]

9. Gomez, V.S.; Barcelò, C.; Serrano, N.; Esteban, M. Antimony film screen-printed carbon electrode for stripping analysis of $\mathrm{Cd}(\mathrm{II}), \mathrm{Pb}(\mathrm{II})$, and $\mathrm{Cu}(\mathrm{II})$ in natural sample. Anal. Chim. Acta 2015, 855, 34-40.

10. Hoĉevar, S.B.; Ogorevc, B.; Wang, J.; Pihlar, B. A Study on Operational Parameters for Advanced Use of Bismuth Film Electrode in Anodic Stripping Voltammetry. Electroanalysis 2002, 14, 1707-1712. [CrossRef]

11. Romanus, A.; Mueller, H.; Kirsch, D. Application of adsorptive stripping voltammetry (AdSV) for the analysis of trace metals in brine. Fresenius J. Anal. Chem. 1991, 340, 371-376. [CrossRef]

12. Economou, A. Recent developments in on-line electrochemical stripping analysis-An overview of the last 12 years. Anal. Chim. Acta 2010, 683, 38-51. [CrossRef] [PubMed]

13. Honeychurch, K.C. Screen-printed electrochemical sensors and biosensors for monitoring metal pollutants. Sci. J. 2012, 2, 1-51. [CrossRef]

14. Guell, R.; Fontas, C.; Aragay, G.; Merkoci, A.; Antico, E. Screen-printed electrodes incorporated in a flow system for the decentralized monitoring of lead, cadmium and copper in natural and wastewater samples. Int. J. Environ. Anal. Chem. 2012, 93, 1-12. [CrossRef]

15. Mozo, J.D.; Carbajo, J.; Sturm, J.C.; Nunez-Vergara, L.J.; Salgado, P.; Squella, J.A. Determination of Nifuroxazide by flow injection linear adsorptive stripping voltammetry on a screen-printed carbon nanofiber modified electrode. Electroanalysis 2010, 24, 676-682. [CrossRef]

16. Dossi, C.; Stropeni, F.; Monticelli, D. Screen Printed Electrode-flow stripping voltammetry for inorganic analysis. In Sensors-Lecture Notes in Electrical Engineering; Compagnone, D., Baldini, F., Di Natale, C., Betta, G., Siciliano, P., Eds.; Springer: Berlin, Germany, 2015; Chapter 25; Volume 319.

17. Pizeta, I.; Omanovic, D.; Branica, M. The influence of data treatment on the interpretation of experimental results in voltammetry. Anal. Chim. Acta 1999, 401, 163-172. [CrossRef]

18. Mocak, J.; Bond, A.M.; Mitchell, S.; Schollary, G. A statistical overview of standard (IUPAC and ACS) and new procedures for determining the limits of detection and quantification: Application to voltammetric and stripping techniques. IUPAC Technical Report 1997. Pure Appl. Chem. 1997, 69, 297-328. [CrossRef]

19. Jakubowska, M.; Piech, R.; Dzierwa, T.; Wcislo, J.; Kubiak, W.W. The evaluation method of smoothing algorithms in voltammetry. Electroanalysis 2003, 15, 1729-1736. [CrossRef]

20. Margoshes, M.; Burns, D.A. Treatise on Analytical Chemistry, Part 1-Theory and Practice, 2nd ed.; Elving, P.J., Mossotti, E.V.G., Kolthoff, I.K., Eds.; Wiley: New York, NY, USA, 1984; Volume 4, p. 413.

(C) 2018 by the authors. Licensee MDPI, Basel, Switzerland. This article is an open access article distributed under the terms and conditions of the Creative Commons Attribution (CC BY) license (http:/ / creativecommons.org/licenses/by/4.0/). 